\title{
A hydro-economic model for managing groundwater resources in semi-arid regions
}

\author{
H. Assaf \\ Department of Civil and Environmental Engineering, \\ American University of Beirut, Lebanon
}

\begin{abstract}
Access to fresh water resources is a limiting factor in the socio-economical development of countries located in semi-arid regions. Water scarcity in these regions, particularly the North Africa and Middle East (MENA) region, is expected to intensify not only due to projected decline in effective precipitation due to climate change and variability, but also due to excessive growth in demand driven by explosive growth in population and improvement in living standards. The meager surface water resources in these regions have already been exploited and significantly polluted leading many governments to deplete their fossil and poorly recharged aquifers mostly to support inefficient and unsustainable agricultural policies and heavy subsidy of municipal water demand.

The paper presents an interactive decision support model developed based on economic principles and simple aquifer representation using the STELLA system dynamics development environment. The model is designed to help water policy makers and managers and other stakeholders formulate and assess alternative water allocation policies among the municipal, industrial and agriculture sectors. Model users will be able to set and interactively manipulate key parameters that influence economic values and sustainability of alternative water policies. These parameters are associated with energy prices, discount rates, planning horizon, demographic factors, willingness-to-pay, hydro-meteorological conditions, aquifer characteristics, and industrial water productivities cropping patterns and agricultural water productivities. Long-term projections of economic value, withdrawals, and remaining water stocks in addition to water demand are presented in tabular and graphical forms.
\end{abstract}


The paper presents a case application of the model for managing the AmmanZarqa aquifer in Jordan. The aquifer is considered a crucial water resource in water poor Jordan.

Keywords: water, decision support, model, aquifer, water management, groundwater, semi-arid, hydroeconomic, STELLA.

\section{Introduction}

Access to fresh water resources is generally a limiting factor in the socioeconomical development of semi-arid regions especially in developing countries. This is particularly true in the North Africa and Middle East (MENA) region. Although this region is historically scarce in water resources, the problem has intensified in modern times due to explosive growth in population and improvement in living standards. The situation reaches critical stages during extended period of droughts, which has increased in frequency possibly linked to global climate change. Water scarcity has been exacerbated by agriculture and human resources development policies that rely on extensive and unsustainable abstraction of renewable and fossil aquifers to subsidize mostly economically inefficient irrigated agriculture. Not only have these policies led to depletion of strategic groundwater reserves, but they have also exposed aquifers to the risk of irreversible salinisation and increased significantly the cost of pumping due to lowering of water tables.

The traditional strategy of managing water scarcity by enhancing water supply through infrastructure development has run its course. Most fresh water resources in the MENA region have been tapped and in fact many have been rendered useless by relentless pollution by domestic, industrial and agricultural waste (Assaf and Saadeh [2]). A more rational strategy should be based on demand management and redistributing water resources to more efficient and sustainable uses with focus on achieving social equity and maintaining environmental services of water resources. However this integrated water resources management approach requires the ability to formulate alternative policies and clear understanding of their projected impact over a given time horizon. This paper reports on the design features and case application of an interactive water policy design model to support these requirements. The model is based on the principles of cost/benefit analysis and simple groundwater hydraulic model.

\section{Methodology}

The hydroeconomic model is designed based on integrating an aquifer hydraulic module and a benefit and cost economic module (see Fig. 1). A water abstraction and allocation policy algorithm is used to formulate alternative schemes for allocating water among different users. Required groundwater abstraction is estimated as the sum of water allocations less non-groundwater supply and passed on to the aquifer module to track changes in water stocks and levels. The latter is used to calculate pumping costs and pass them on to the economic 
module. This tight integration facilitates seamless assessment of the impact of water use on water levels and in turn cost of water provision. The model is implemented using STELLA System Dynamics (SD) programming environment that supports on-the-fly display of results and high interaction by users that include modifying variables and policies during simulation. The theoretical basis of the model and its STELLA implementation are presented in the following sections.

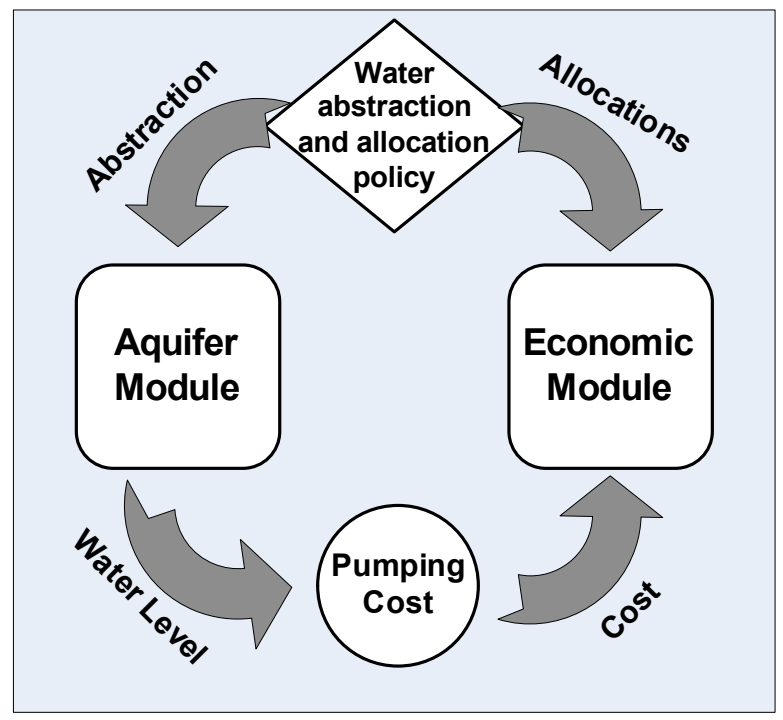

Figure 1: Hydroeconomic model architecture.

\subsection{The model theoretical framework}

The economic module determines the net present value (NPV) of different groundwater abstraction and water allocation policies. The NPV value is calculated as the sum of net benefits (NB) achieved by water users and time discounted over a given planning horizon, T, as expressed in eqn. (1) (adapted from Griffin [5]):

$$
\mathrm{NPV}=\sum_{t=0}^{T}\left(\frac{\sum_{i=1}^{N} N B(t)}{(1+d)^{t}}\right)
$$

where $t$ is the year index, $i$ is the index of water user, $N$ is the total number of water users, $N B_{i}(t)$ is the net benefit of user $i$ during year $t$, and $d$ is the discount rate.

The NB is calculated as the product of water productivity (WB) and the amount of water used. The WB is calculated depending on the type of water user. WB for agricultural users is calculated as the difference between gross benefit (value added) of agricultural produce and the costs of production 
including capital, land, and the cost of water pumping. The latter is calculated separately in the module since it is a function of groundwater levels, which are estimated via the aquifer module. Water pumping cost, $C p$, is calculated based on eqn. (2) (Schiffler [7]):

$$
C_{P}=\frac{0.0027 \times H}{e} E C+M N+A C
$$

where $H$ is the depth to water level, $e$ is the pump efficiency, $E C$ is the cost of energy per $\mathrm{kWh}, M N$ is the maintenance cost, and $E C$ is the abstraction charge.

The municipal water productivity is calculated based on the consumer's willingness-to-pay and water treatment and delivery costs. Industrial water productivity is estimated based on the benefit attributed to water less costs related to treatment and pumping.

The groundwater stocks and water levels are calculated via the aquifer module which is based on simple aquifer representation as expressed in eqn. (3) (Gisser [1]) and adapted from Schiffler [7] as follows:

$$
\frac{\Delta H}{\Delta t}=\left(R-W-W_{n}\right) /(A \times S)
$$

where $R, W_{n}$ and $W$ are recharge (natural and artificial), natural discharge to surface water, and withdrawal from aquifer, respectively all in units of volume per year, and $A$ and $S$ are the area and storage coefficient, respectively, of the aquifer.

\subsection{Implementation of the model in STELLA}

STELLA is a leading visual System Dynamics (SD) programming environment (ISEE [6]). In the SD approach, dynamic systems are represented in terms of a set of components interacting via positive and negative feedback loops which give rise to a dynamic behaviour that emulates real system's behaviour. An important feature of the SD architecture is the support for interactive integration of users input during simulation. This flexibility along with the highly and interactive visual environment of STELLA facilitates development of tools to support stakeholder participation, which is an important element in integrated water resource management (Winz and Brierley [8]).

The hydroecomomic model was implemented in STELLA to assess water allocation polices from a single aquifer to water users aggregated into three users representing agricultural, municipal and industrial sectors. Several interlinked modules were developed to represent the various components of the hydroeconomic model. Due to space limitation only two of the key components (the aquifer and NPV modules) of the STELLA model are briefly described in this paper.

\subsubsection{The aquifer STELLA module}

The Aquifer hydraulic module is implemented in STELLA as shown in Fig. 2. The aquifer volume is represented by a stock $\square$ which as a STELLA language 
element represents accumulation of a given quantity. The change in aquifer volume is captured through a recharge and discharges flows $\vec{\sigma}$. Variables are implemented as converters, symbolized by circles, $\bigcirc$, each containing a given value or an array of values. The combination of the aquifer stock, discharge/recharge flows, and converter in addition to the lower set of stock, flows and converters represent the aquifer differential equation (eqn. (3)).

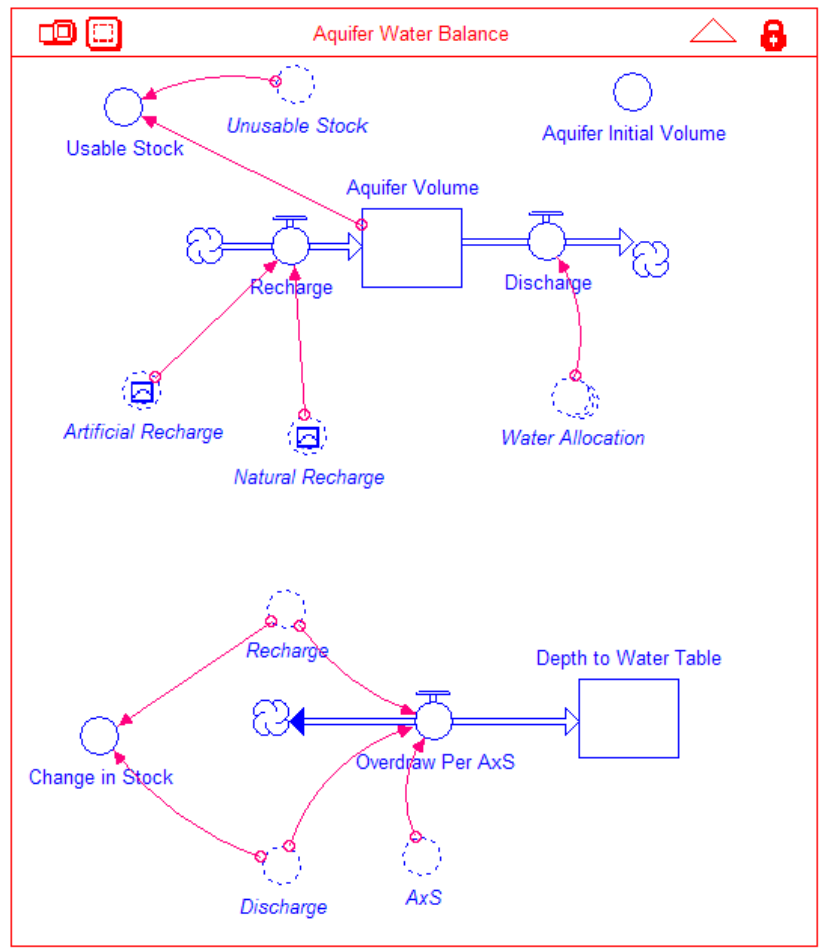

Figure 2: The aquifer Stella module.

\subsubsection{The economic STELLA module}

The economic STELLA module calculates in parallel the NPVs for the three water demand sectors. Each NPV is represented by a pair of flow-stock elements. Inflow and outflow from these elements are maintained via a set of converter arrays (Fig. 3).

\section{Case study: management of the Amman-Zarqa Groundwater Basin, Jordan}

\subsection{Physical setting}

Located in the drier south-eastern part of the Levant, Jordan is very poor in water resources with over $90 \%$ if its $90,000 \mathrm{~km}^{2}$-area receiving less than $200 \mathrm{~mm} /$ year (Abdulla et al. [1]). Jordan's population of 5 million people concentrated mostly 


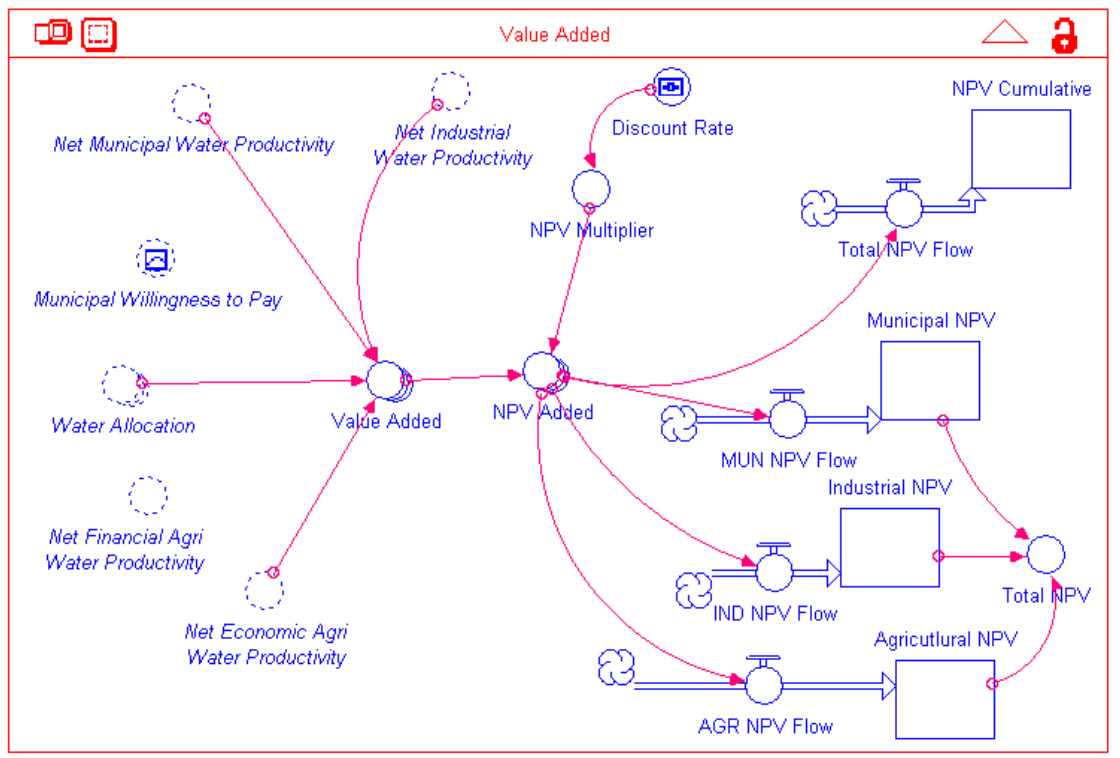

Figure 3: The economic STELLA module.

in the north-western highlands has a water demand of 1,200 MCM/year (Millions Cubic Meters per year) which despite being one of the lowest per capita in the world surpasses significantly the $870 \mathrm{MCM} /$ year of the country's renewable freshwater resources. The shortfall is met by overabstracting groundwater water resources and to a limited extent by wastewater reuse in agriculture.

The total natural recharge of Jordan's aquifers is estimated about 275 $\mathrm{MCM} /$ year. Over $1 / 3$ of that amount ( $88 \mathrm{MCM} /$ year) is attributed to the AmmanZarqa Groundwater Basin (AZB) which originates in Jebel Arab in Syria and extends southwest across the border to meet the Rift Side Wadi Basin in the west (Fig. 4). Covering an area of $4,074 \mathrm{~km}^{2}$ in Jordan and $512 \mathrm{~km}^{2}$ in Syria, the AZB is home to the largest urban and industrial centres in Jordan (Fig. 5) (Chebaane et al. [3]). Its relatively sizable stock and proximity to the heavily populated areas make it a very significant and strategic water resource.

The AZB was heavily utilized during the 1970s and early 1980s to support a government program to encourage settlement and socio-economic development of the local mostly nomadic population. The landscape of the region has changed considerably from an arid region to a land of orchards and vegetable farms especially during the 1980s when local and external demand of agricultural product has grown significantly. However, these developments had resulted in sharp reduction in groundwater water levels combined with significant increase in salinity levels rendering unusable several wells especially in the lower southern region of the AZB. The lowering of water levels combined with phenomenal increase in energy prices have increased pumping costs and consequently total production costs to unfeasible levels. Findings from a recent 


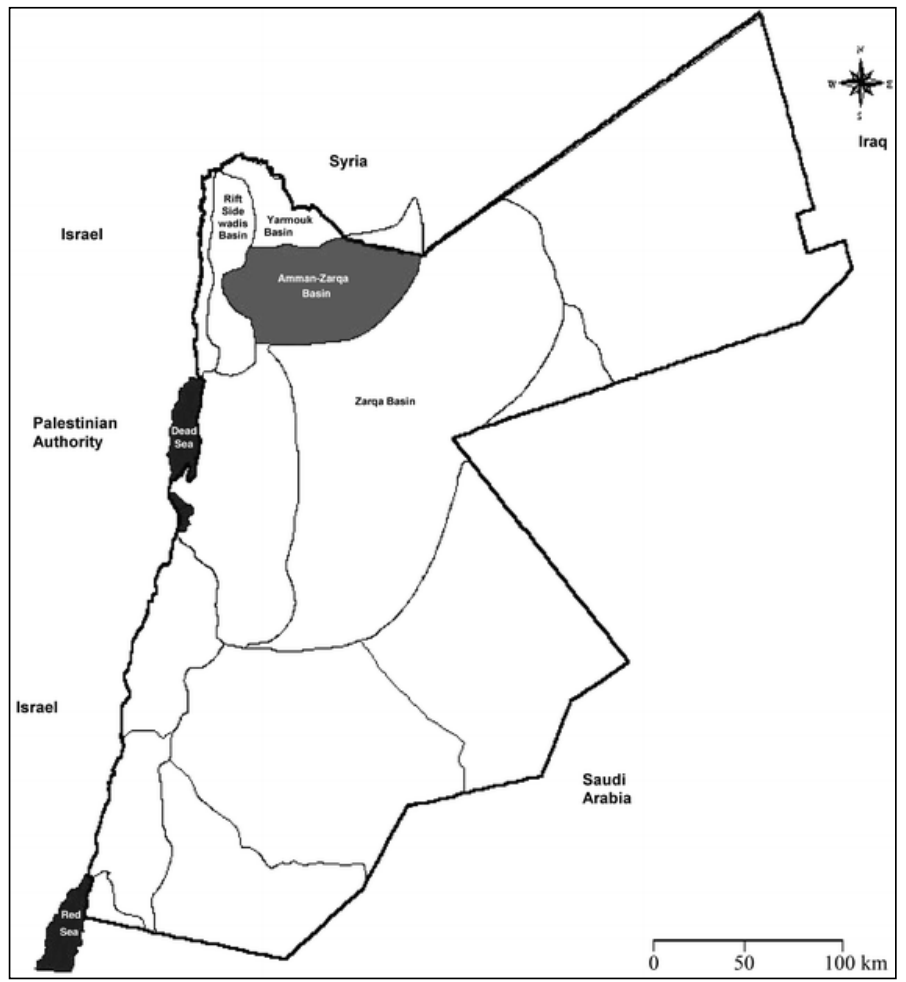

Figure 4: $\quad$ Location of the Amman-Zarqa Basin (Source: Chebaane et al. [3]).

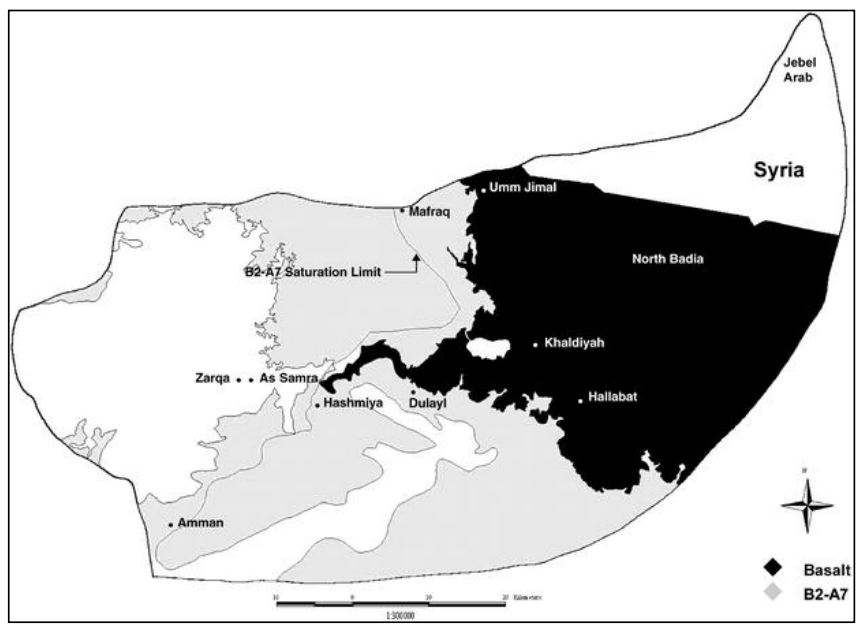

Figure 5: The AZB area and main geological features (Source: Chebaane et al. [3]). 
study sponsored by the USAID/Jordan indicate that the unsustainable abstraction of the AZB is estimated to result in a total loss of US\$74 million due to increased cost of pumping, well rehabilitation, abandonment of farms, and crop yield losses (Chebaane et al. [3]).

\subsection{AZB model setup and design}

In assessing options for managing water resources of the AZB, Chebaane et al. [3] emphasized the importance of participation and active involvement of stakeholders especially farmers who would be greatly impacted by any introduced measures to control the depletion of the aquifer. The AZB model was setup to facilitate the application of this participatory approach and provide insight into the roles of key factors such as discount rate, energy cost, planning horizon, water productivity and customer willingness-to-pay in influencing the economic values of alternative water resources management options. The setup process involved designing a user-friendly and interactive interface and selection of model components and their level of aggregation.

The user interface of the AZB model was designed as a set of sub-interfaces accessed via a central interface referred to as the Main Control Board (MCB) (Fig. 6). The multi-layer graph in the upper right corner of the MCB displays the progress of key variables such as the NPV and groundwater level throughout the simulation run. Hidden layers of the graph can be displayed by clicking on its bottom left corner. The model is programmed to prompt the user with messages if a given threshold, e.g. minimum groundwater level, is exceeded.

The array of buttons on the upper left side of the MCB are used to access subinterfaces to assign/edit variables related to economic, hydrological and demand data, simulation parameters and policies for depleting the aquifer. For example, clicking on the "Economic Data" button brings the Economic Data sub-interface

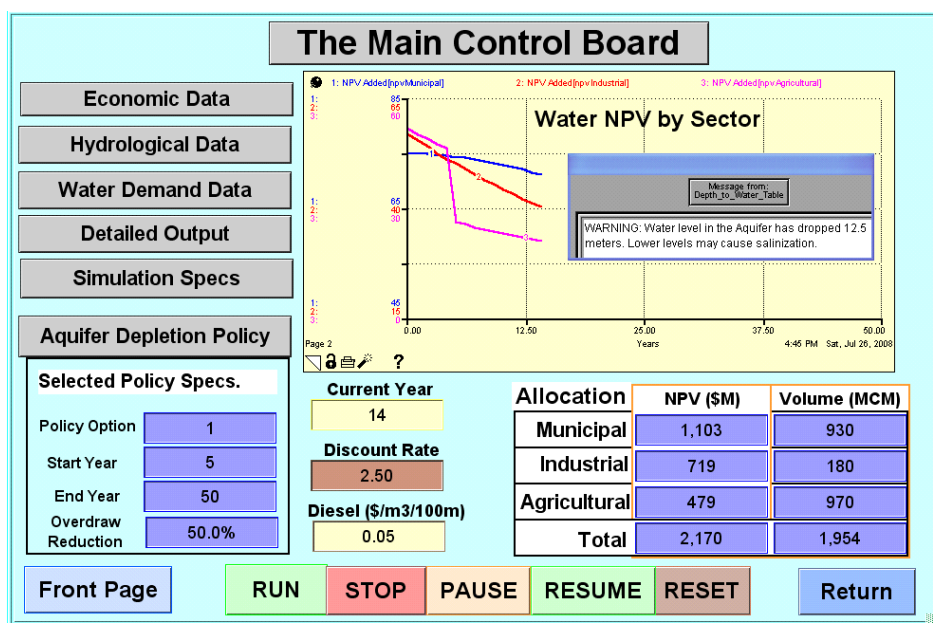

Figure 6: The main user-interface of AZB hydroeconomic model. 
into display where the user can assign and edit the discount rate and parameters for determining farming water productivities and cost of pumping (Fig. 7). The user can then return to the main button by clicking the "Main" button on the bottom panel. To define aquifer depletion policy the user clicks on the corresponding button in the MCB which brings the policy setting sub-interface into view (Fig. 7). The user can then set the beginning and end years of the policy and the maximum $\%$ of overdraft permitted. The user can also choose to select a predefined policy using the dial control element. The other userinterfaces are not presented here due to limited space in the paper.

Several values of key parameters are shown at the bottom of the graph in the MCB. The bottom part of the MCB contains several buttons to control the flow of simulation. One of the unique interactivity features of the model is the ability to pause the simulation, edit parameters and resume simulation using the modified parameter values.
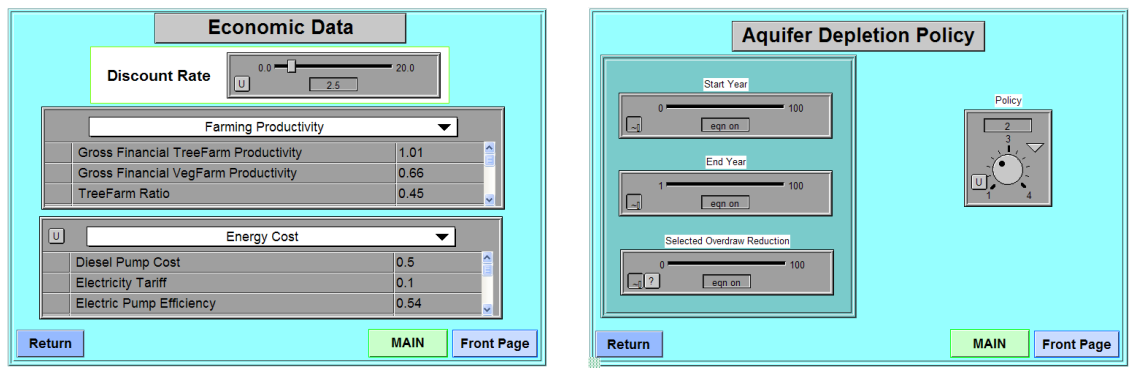

Figure 7: The economic and aquifer depletion policy data sub-interfaces.

\subsection{A sample application of the AZB Model}

As discussed earlier, the AZB model is designed to support several types of applications including developing alternative water allocation policies, assessing the impact of key factors on the economic values of water policies, and using the model as an informational and educational tool.

In this paper, a series of model simulation runs were conducted to assess three aquifer depletion and water allocation policies over a period of 50 years. Adopted from Schiffler [7], these policies are deigned to explore the options of managing the AZB, which as mentioned earlier is being depleted at an alarming rate to support irrigated agriculture in the area. The first policy places no restrictions on overdraft of the aquifer to satisfy the three municipal, industrial and agricultural users until the aquifer is depleted to point beyond which extraction is not feasible. Upon reaching this level, water is allocated to first satisfy municipal and then industrial demand with the remaining left to agriculture. The second policy is similar to the first policy with the exception that overdraft is restricted to $50 \%$ of demand above recharge. The third policy allows no depletion of aquifer with abstraction equal to recharge. As in the first two policies, available water is first allocated to municipal, then industrial with the remaining allocated to agriculture. 
The simulations were based on the following assumptions which are mostly obtained from the findings of an extensive survey and analysis study conducted by the German Development Institute (GDI) (Schiffler [7]):

- The aquifer is estimated to have a total stock of 1,700 MCM, half of which can be feasibly extracted. The aquifer is assumed to have a storage coefficient of $3 \%$ and an initial water level of 100 meters below ground surface.

- Annual municipal water demand is assumed constant at $62 \mathrm{MCM}$ with a consumer's willingness-to-pay price increasing linearly from $1.3 \$ / \mathrm{m}^{3}$ in the first year to $2.8 \$ / \mathrm{m}^{3}$ in the $50^{\text {th }}$ year.

- Annual industrial water demand is assumed constant at $12 \mathrm{MCM}$ with an industrial gross water productivity (excluding the cost of pumping) of $4.75 \$ / \mathrm{m}^{3}$.

- Agricultural water demand is assumed constant at $90 \mathrm{MCM}$. 55\% of the farms are used to grow vegetable with the remaining farms are planted with productive trees. Gross water productivities (excluding pumping costs) are assumed $0.66 \$ / \mathrm{m}^{3}$ and $1 \$ / \mathrm{m}^{3}$ for vegetable farms and tree farms, respectively.

- Effective rate of protection of agricultural product is estimated at $25 \%$.

- $73 \%$ of irrigation water is assumed to be extracted using diesel pumps at a cost of 50 cents per $\mathrm{m}^{3}$ per 100 meter lift. The rest and all industrial water are abstracted using electric pumps at a cost of 10 cents per kWH.

The simulations results for three alternative discount rates $(0 \%, 2.5 \%$ and $10 \%)$ are presented in Table 1 . The results clearly show that the agricultural sector produces a much lower return on water in comparison to the municipal and industrial sectors as indicated by the corresponding the NPV per $\mathrm{m}^{3}$ under all policies and for all discount rates. This discrepancy is attributed to the intense water scarcity and high energy prices. Water scarcity drives up the municipal willingness-to-pay. Energy prices constitute a major component of agricultural production costs.

The results indicate that the non-depletion policy (\#3) produces the best return on water irrespective of the selected discount rate. This is attributed to the fact that the municipal and industrial demands (a total of $62+12=74 \mathrm{MCM}$ ) are completely satisfied by the yearly aquifer recharge of $88 \mathrm{MCM}$, and consequently overdraft is only need to satisfy the much less productive agricultural sector. It is therefore highly recommended to conserve the use of this strategic water resource and plan to confine mostly for municipal and industrial demand.

Simulation results highlight the role discount rates play in assessing the value of long-term water resources project. Higher discount rates significantly suppress the net present value of future water resources which may encourage planners to favour early utilization of these resources. Lower discount rates place higher values on future water resources which encourages more conservation and more sustainable water resources management. 
Table 1: $\quad$ AZB management policy simulation results.

\begin{tabular}{|c|c|c|c|c|c|c|c|c|c|}
\hline \multirow[t]{2}{*}{$D=0 \%$} & \multicolumn{3}{|c|}{ Policy \#1 } & \multicolumn{3}{|c|}{ Policy \#2 } & \multicolumn{3}{|c|}{ Policy \#3 } \\
\hline & \begin{tabular}{|l|} 
NPV \\
(\$M) \\
\end{tabular} & $\begin{array}{c}\text { VOL } \\
(\mathrm{MCM})\end{array}$ & $\begin{array}{c}\text { NPV/VOL } \\
\left(\$ / \mathbf{M}^{3}\right) \\
\end{array}$ & $\begin{array}{l}\text { NPV } \\
\text { (\$M) } \\
\end{array}$ & $\begin{array}{c}\text { VOL } \\
\text { (MCM) }\end{array}$ & $\begin{array}{c}\text { NPV/VOL } \\
\left(\$ / \mathbf{M}^{3}\right) \\
\end{array}$ & $\begin{array}{l}\text { NPV } \\
(\$ M) \\
\end{array}$ & $\begin{array}{c}\text { VOL } \\
(\mathrm{MCM})\end{array}$ & $\begin{array}{c}\mathbf{N P V} / \mathrm{VOL} \\
\left(\$ / \mathbf{M}^{3}\right) \\
\end{array}$ \\
\hline MUN & 6,294 & 3,100 & 2.03 & 6,294 & 3,100 & 2.03 & 6,294 & 3,100 & 2.03 \\
\hline IND & 2,811 & 600 & 4.69 & 2,811 & 600 & 4.69 & 2,814 & 600 & 4.69 \\
\hline AGR & 304 & 1,462 & 0.21 & 306 & 1,462 & 0.21 & 167 & 700 & 0.24 \\
\hline TOT & 9,409 & 5,162 & 1.82 & 9,411 & 5,162 & 1.82 & 9,275 & 4,400 & 2.11 \\
\hline \multirow{2}{*}{$D=2.5 \%$} & \multicolumn{3}{|c|}{ Policy \#1 } & \multicolumn{3}{|c|}{ Policy \#2 } & \multicolumn{3}{|c|}{ Policy \#3 } \\
\hline & \begin{tabular}{|l|} 
NPV \\
(\$M) \\
\end{tabular} & $\begin{array}{c}\text { VOL } \\
(\mathrm{MCM})\end{array}$ & $\begin{array}{c}\text { NPV/VOL } \\
\left(\$ / \mathbf{M}^{3}\right) \\
\end{array}$ & $\begin{array}{l}\text { NPV } \\
\text { (\$M) } \\
\end{array}$ & $\begin{array}{c}\text { VOL } \\
\text { (MCM) }\end{array}$ & $\begin{array}{c}\text { NPV/VOL } \\
\left(\$ / \mathbf{M}^{3}\right) \\
\end{array}$ & $\begin{array}{l}\text { NPV } \\
(\$ M) \\
\end{array}$ & $\begin{array}{c}\text { VOL } \\
(\mathrm{MCM})\end{array}$ & $\begin{array}{c}\mathbf{N P V} / \mathrm{VOL} \\
\left(\$ / \mathbf{M}^{3}\right) \\
\end{array}$ \\
\hline MUN & 3,394 & 3,100 & 1.09 & 3,394 & 3,100 & 1.09 & 3,394 & 3,100 & 1.09 \\
\hline IND & 1,634 & 600 & 2.72 & 1,635 & 600 & 2.73 & 1,636 & 600 & 2.73 \\
\hline AGR & 231 & 1,462 & 0.16 & 217 & 1,462 & 0.15 & 97 & 700 & 0.14 \\
\hline TOT & 5,259 & 5,162 & 1.02 & 5,246 & 5,162 & 1.02 & 5,127 & 4,400 & 1.17 \\
\hline \multirow[t]{2}{*}{$D=10 \%$} & \multicolumn{3}{|c|}{ Policy \#1 } & \multicolumn{3}{|c|}{ Policy \#2 } & \multicolumn{3}{|c|}{ Policy \#3 } \\
\hline & \begin{tabular}{|l|} 
NPV \\
(\$M)
\end{tabular} & $\begin{array}{c}\text { VOL } \\
(\mathrm{MCM})\end{array}$ & $\begin{array}{c}\mathbf{N P V} / \mathrm{VOL} \\
\left(\mathbf{\$} / \mathbf{M}^{3}\right)\end{array}$ & $\begin{array}{l}\text { NPV } \\
\text { (\$M) } \\
\end{array}$ & $\begin{array}{c}\text { VOL } \\
(\mathrm{MCM})\end{array}$ & $\begin{array}{c}\text { NPV/VOL } \\
\left(\$ / \mathbf{M}^{3}\right) \\
\end{array}$ & $\begin{array}{l}\text { NPV } \\
\text { (\$M) } \\
\end{array}$ & $\begin{array}{c}\text { VOL } \\
(\mathrm{MCM})\end{array}$ & $\begin{array}{c}\mathbf{N P V} / \mathrm{VOL} \\
\left(\$ / \mathbf{M}^{3}\right) \\
\end{array}$ \\
\hline MUN & 1,076 & 3,100 & 0.35 & 1,076 & 3,100 & 0.35 & 1,076 & 3,100 & 0.35 \\
\hline IND & 613 & 600 & 1.02 & 613 & 600 & 1.02 & 614 & 600 & 1.02 \\
\hline AGR & 146 & 1,462 & 0.10 & 113 & 1,462 & 0.08 & 37 & 700 & 0.05 \\
\hline TOT & 1,835 & 5,162 & 0.36 & 1,802 & 5,162 & 0.35 & 1,727 & 4,400 & 0.39 \\
\hline
\end{tabular}

MUN: Municipal IND: Industrial AGR: Agricultural.

\section{Summary and conclusions}

The paper presents the methodology and case study application of a hydroeconomic model for managing groundwater resources in semi-arid regions. The model was developed using STELLA system dynamics programming environment based on economic and simple groundwater hydraulic principles. The model accounts for several economical, hydraulic and planning factors that significantly impact the economic value of groundwater utilization including discount rate, cost of energy, planning horizon, groundwater levels and available stocks, consumers willingness-to-pay, industrial water productivity and cropping patterns.

The model was applied to simulate management of groundwater resources in the Amman-Zarqa Groundwater Basin (AZB), which has been excessively abstracted mostly for the benefit of irrigated agriculture in the previously barren area. These practices, which persisted over a few decades, have caused steep decline in groundwater water levels and sharp increase in water salinity.

Three groundwater policy alternatives were simulated by the AZB model. The first fully accommodates demand and allows uncontrolled overdraft until the 
feasibly retrievable stock is exhausted. The second policy restrain overdraft to half of the demand, while the third allows no overdraft. All policies are based on satisfying the municipal demand first, followed by industrial demand and then by agricultural demand.

The results have shown that agricultural water economic return is very low in comparison to municipal and industrial counterparts. This is mainly a result of the acute water scarcity in Jordan, which drives up the consumers' willingnessto-pay, and the high prices of energy, used mostly in pumping, which constitute a significant portion of the agricultural production cost.

The results also show that the no-depletion policy produces the highest return which indicates the need to conserve the use of this strategic water resource and reserve its use for the highly productive municipal and industrial sectors. This is an important issue considering that the AZB provides a relatively low cost water supply in comparison to those expected from capital-intensive water supply projects with high-cost operation and maintenance, including the Disi pipeline, currently under consideration by Jordan.

The results underscore the importance of selecting discount rates for assessing the economic values of water resource management alternatives. Higher discount rates values may significantly undervalue water conservation measures.

\section{References}

[1] Abdulla, F., Eshtwai, T. and H. Assaf, Assessment of the Impact of Potential Climate Change on the Water Balance of a Semi-arid Watershed. Water Resources Management, 2008.

[2] Assaf, H. and M. Saadeh, Assessing water quality management options in the Upper Litani Basin, Lebanon, using an integrated GIS-based decision support system. Environmental Modelling \& Software, 23(10-11): 13271337, 2008.

[3] Chebaane, M., El-Naser, H., Fitch, JB., Hijazi, A. and A. Jabbari, Participatory groundwater management in Jordan: development and analysis of options. Hydrogeol J 12(1):14-32, 2004.

[4] Gisser, M., Groundwater: Focusing on the Real Issue. Journal of Political Economy. 91(6), pp.1001-1027, 1983.

[5] Griffin, R., Water Resource Economics: The Analysis of Scarcity, Policies, and Projects, Cambridge, Mass., MIT Press, 2006.

[6] ISEE Systems, STELLA: Systems thinking for education and research. Accessed at http://www.iseesystems.com/softwares/Education /StellaSoftware.aspx on May 10, 2009.

[7] Schiffler, M., The Economics of Groundwater Management in Arid Countries. GDS Book Series II. Frank Cass, London, 1998.

[8] Winz, I., and G. Brierley, The use of system dynamics simulation in integrated water resources management. Proceedings of the 25th International Conference of the System Dynamics Society, System Dynamics Society, Boston, Massachusetts, 2007. 